\title{
An Investigation into the Relationship between Adults' Levels of Education-Related Epistemic Freedom and Epistemic Violence
}

\author{
Osman Yilmaz KARTAL ${ }^{1}$, Akan Deniz YAZGAN ${ }^{1} \&$ Esranur AVCI ${ }^{2}$ \\ ${ }^{1}$ School of Education, Çanakkale Onsekiz Mart University, Çanakkale, Turkey \\ ${ }^{2}$ Institute of Educational Science, Çanakkale Onsekiz Mart University, Çanakkale, Turkey \\ Correspondence: Osman Yılmaz KARTAL, School of Education, Çanakkale Onsekiz Mart University, Çanakkale, \\ Turkey. Tel: 90-533-046-2509. E-mail: oykarta179@yahoo.com
}

Received: July 15, $2018 \quad$ Accepted: August 29, $2018 \quad$ Online Published: September 27, 2018

doi:10.5539/ies.v11n10p96

URL: https://doi.org/10.5539/ies.v11n10p96

\begin{abstract}
The present study investigates the relationship between epistemic freedom and epistemic violence. The problematization was based on adults. Due to adults' responsibilities for education, the study focuses on adults' levels of education-related epistemic freedom and epistemic violence. The research problem was analyzed with the correlational research model. The sample consists of 129 participants between 22 and 67 years. The data were collected with epistemic violence-freedom scale. The study revealed that adults' level of accepting education-related epistemic violence and resorting to education-related epistemic violence were "moderate" and "low", respectively, while their enjoyment of epistemic freedom in the past was between "moderate" and "high" and their tendency to education-related epistemic freedom was "high". The authors found a significant, negative, and weak relationship between adults' levels of "resorting to epistemic violence" and levels of "enjoyment of education-related epistemic freedom in the past" and "their tendency to education-related epistemic freedom". The authors also observed a significant, positive, and moderate relationship between adults' levels of "enjoyment of education-related epistemic freedom in the past" and "their tendency to education-related epistemic freedom". The authors suggest that individuals should be provided with a freedom-based education and setting.
\end{abstract}

Keywords: epistemology, epistemic freedom, epistemic violence, adult, education

\section{Introduction}

Individuals cognitively interact during communication. This interaction may occur between individuals and moreover between individuals and media via media tools. Media as the mediator conveys producers' information with such tools as books, television shows, internet blogs, and Wikipedia. In the communication process in which source and receiver obligatorily participate in, the party which holds the authority over information maintains the power thanks to its role as the source. This sometimes leads to a one-way communication. In such a case, quality of the receiving party' cognitive behaviors is important. Just as the receiver accepts the transmitted information, he/she can adopt a suspicious attitude towards it. Further, he/she may not accept the authority of the source and himself/herself produce information. What are the parameters determining these cognitive approaches of the receiver? What kind of differences can be observed between a non-inquisitive and inquisitive receiver? The answers to these questions account for the epistemic efforts guiding an individual's individual existence. From the moment of birth onwards, individuals are exposed to an intensive "bombardment" of information. They cannot resist this imposition until they develop a cognitive maturation or readiness that will allow them to process and manipulate information. Therefore, it is important that individuals should be offered social roles to support them cognitively and that an environment should offer such a culture to promote epistemic freedom and to resist epistemic violence. However, it is hard to suggest that sub-cultures (media, family, school, friends, etc.) as cultural mediators are functional in this matter, which is a significant indicator of why the critiques of Frankfurt School are still true in the 2000s. Individuals' taking epistemic risk in their search of knowledge and developing their epistemological beliefs to the highest level are among the primary goals of the 2010s.

\subsection{State of Art}

Individuals should maintain a high level of epistemic vigilance in their interaction with knowledge (Sperber, Clement, Heintz, Mascaro, Mercier, Origgi, \& Wilson, 2010). The habit of trusting individuals competent in 
knowledge-related issues promotes epistemic trust and over time leads to the emergence of a culture of trust to other roles labeled as "the other" (Origgi, 2012). Thus, such behavioral patterns as considering any kind of information on social media to be true, accepting information on Wikipedia without questioning it, manipulation of online contents, propaganda, and failure to detect misinformation have come to be listed among social rituals of the 2010s. Moreover, the long-held contention that textbooks, news, academic texts cannot be questioned still persists. In such a case, the following question arise (Sperber et al., 2010): How could we trust others as sources of information? Not only the trustworthiness of information but also the validity of the source is important (Daukas, 2006). How could we achieve this in the information age in which information overload prevails? On the other hand, as in the ideologies adopting the slogan "We think for you." will we continue accepting the world created by information elites? One of the basic solutions to the above problem is to help individuals improve their epistemic skills and achieve the relativity stage or epistemological belief (Hofer \& Pintrich, 1997; Schommer, 1994; Schommer, 1998; Schommer-Aikins, Duell, \& Barker, 2003). How can it achieved in a process where epistemic trust is observed in every sub-unit of a culture? Individuals should exchange knowledge in their daily routines (use of social media, communication with others, etc.), but while doing so they should adopt an inquisitive and suspicious attitude towards the roles attributed to knowledge authorities and maintain a dynamic attention level (Koenig \& Harris, 2007; Shafto, Eaves, Navarro, \& Perfors, 2012). It is highly possible that this analysis will work properly. Nevertheless, what are the elements to achieve this behavior? A search for answer to this question has revealed the components "achievement of epistemic freedom, individual's taking epistemic risk, prevention of epistemic oppression and epistemic violence, and promoting individual's epistemic belief (Hofer \& Pintrich, 1997; Kıncal, Kartal, \& Yazgan, 2018; Velleman, 2000; Zagzebski, 2012). Unless educational steps are taken in relation to these components, it is a high probability that individuals unconditionally trust "others".

Epistemic oppression refers to epistemic alienation intended by the authority to prevent individuals from contributing to knowledge production (Dotson, 2012). Epistemic oppression occurs as the reflection of cognitive authorities and denotes a structure where receivers take no epistemic risk and internalize knowledge and truths offered by authority (Quiamzade, Mugny, and Falomir-Pichastor, 2009). In such a setting, receivers quit producing "epistemes" and turn into epistemically dependent individuals (Gelfert, 2013). In structures having internalized epistemic authority, the authority imposes its own view of reality and prevents/choose not to create the clime that will allow for the production of alternative ideas.

Epistemic oppression is considered as a system of imposition decisive in the formation of macro-level cognitive structures including individuals' perspectives on life, worldview, and ideology and micro-level cognitive structures including daily routines. In this system, it is imperative that an environment to allow learners to form micro- or macro-level cognitive structures by avoiding impositions. For example, questioning whether individuals' cognitive structures concerning democracy, human rights, various ethnic structures, etc. are the consequences of their own choices or accepted/adopted as a result of epistemic oppression. This is where epistemic vulnerability comes in (Chinnery, 2013; Logue, 2013).

Plato's Cave Allegory is an illustrative description of epistemic vulnerability. It seems very difficult to get out of the cave if one does not realize or try to eliminate epistemic vulnerability. The way out is embedded in the search for the unknown and struggle for it, acceptance that we are in a state of misrecognition, and attempts to discover the world outside (of our own cognitive reality) (Logue, 2013). It would not be wrong to claim that an individual trapped in the cave are not in pursuit of the life outside. Knowledge is a set of codes comprising the algorithm of individuals' lives (as in the argumentation in the 2010s). Thus, an inquiry into who has written these codes and what kind of a program has been devised in learners is the fundamental educational requirement. The quality of this inquiry greatly matters for the functionality of the analysis. According to Logue (2013), epistemology is to question the nature, methodology, and limits of knowledge creation. Here, one could rightfully expect the inclusion of philosophical interrogations into knowledge in daily routines: "Questioning the significance of knowledge with the questions 'what don't we know?', 'what should we know?', and 'what don't we want to know?' as much as with the questions 'what can be known?' and 'who can know how?". Hence, epistemological questioning is crucial to get out of the cave. The analysis of educational practices (formal or non-formal) offered at an institutional level will reveal that education impedes free and critical thinking and an effective social change. Thus, educational processes may occur in a way to increase learners' dependency on authority (teacher as source of knowledge rather than a guiding teacher, monopolized media, sources of knowledge trapped in blindness of knowing and failing to improve itself, etc.) (Moroz, 2015). This is a symptom of epistemic violence. Galván-Álvarez (2010) defines epistemic violence as a kind of violence practiced via knowledge and as a fundamental component of the process to build hegemony.

The related literature shows that an increasing attention has been attributed to epistemic violence over the last 
years. Al-Mahadin (2004) has analyzed gender perception, gender roles, and gender-focused stereotypes created with epistemic violence and emphasized education's potential to turn into a tool of epistemic violence. Galván-Álvarez (2010) has carried out an analysis of epistemic violence in relation to media and revealed media's potential to become a vessel of epistemic violence. Moroz (2015) has discussed knowledge and reality as a tool of epistemic violence, passed some criticisms, and made some suggestions in relation to education institutions. Marker (2003) has analyzed and criticized the epistemic violence in anthropology: Marker claims that anthropologists establish reality to strengthen their careers and boost their interests rather than present the facts of local cultures. Research into parameters similar to epistemic violence should be mentioned too. Quiamzade, Mugny, and Falomir-Pichastor (2009) have analyzed the effects of epistemic constraint on the formation of epistemic dependence and of teachers' authoritarian and democratic approaches on students' achievements. It is necessary to attend to epistemic violence whose direct and indirect relationship and interaction with education has been researched and investigate its effects on different educational practices.

Epistemic dominance resulting in or from epistemic violence should be analyzed. "Ignorance/illiteracy" is among the indicators of epistemological dominance. Logue (2013) claims that ignorance/illiteracy is established consciously and exploited to close down community and eliminate crimes in various legal and cultural spheres. It is professionally and consciously devised to maintain the created ignorance and power. Besides, epistemological dominance is defined as culturalism. Culturalism can be described as an academic and pedagogical stance emphasizing that mainstream culture and knowledge has a global and universal character and should be accepted by the others (domestic and local culture and knowledge) (Battiste, 2004; cited in Andreotti, Ahenakew, \& Cooper, 2011). The primary issue to be considered and criticized here is what the criteria of the mainstream culture and universality of knowledge are, who and what these criteria serve, why epistemological pluralism is chosen over epistemological majority. In this context, serious criticism is raised against epistemological dominance (Andreotti, Ahenakew, \& Cooper, 2011). Deloria (1995) defines epistemological dominance as white lies. It refers to epistemic methods the strong employ to establish cultural superiority over the weak. Here the strong should be defined. This sometimes results from the quantitative power of the majority and sometimes from the authority small groups (capital holders, media tycoons, politicians, decision-makers, intellectual communities, intelligentsia, etc.) hold.

In order to eliminate the above epistemological constraints, the basic approach is to establish the clime of epistemic freedom and maintain it. Epistemic freedom is referred to as freedom of expressing clashing propositions without the risk/fear of being wrong/incorrect (Velleman, 2000). Thusly, individuals/learners come to enjoy the opportunity to take epistemic risk in relation to any kind of knowledge or reality. Bastien (2004) has made suggestions concerning the characteristics of intellectual freedom and mono-epistemicism (mono-centric sources of knowledge-schools, universities, monopolized media, etc.) to sort out epistemological constraints/handicaps. For intellectual freedom, students are required to improve their knowledge, skills, and abilities pertaining to complexity, diversity, and uncertainty. This is because they need to face the fact that there are options other than the ones offered by mono-epistemicism and these alternative options are not presented consciously or discovered yet. It is stressed that learners will search for epistemological freedom when their awareness and competencies are improved.

The democratic attitude students are presented with during education signifies an opportunity to lay the groundwork for epistemic freedom and prevent epistemic violence. Previous research suggest that while democratic approach promotes epistemic freedom against authority, authoritarian approach boosts epistemic dependence on authority (Mugny, Chatard, \& Quimzade, 2006; Mugny, Quimzade, \& Trandafir, 2006). Marker's (2003) truth dilemma epitomizes epistemic violence: "The truth that is told and the truth that is sold". In pursuit of truth, if learners deem truth as a merchandise to buy, then "Culture Industry" of Frankfurt School should be taken into account (Henning, 2017). What truth of what quality is sold to learners?

The above analysis mandates the discussion of the presence and acceptance of epistemic freedom and epistemic violence in education. In this context, an investigation into adults who have finished their formal education process and serve as intermediary for others' education and their approach and acceptance concerning epistemic freedom and epistemic violence is believed to offer some practical solutions. Thusly, some judgments can be passed in relation to the levels of epistemic freedom and epistemic violence and their interrelations.

\section{$1.2 \mathrm{Aim}$}

The present study investigates the relationship between adults' levels of attitudes towards education-related epistemic freedom and epistemic violence. To this end, the following aims were discussed: 
- Adults:

- What are adults' levels of accepting education-related epistemic violence?

- To what extent do they resort to education-related epistemic violence?

- What were adults' levels of epistemic freedom in their educational background?

- What are their tendencies of education-related epistemic freedom?

- Is there a relationship between adults' levels of accepting epistemic violence, levels of practicing epistemic violence, levels of having epistemic freedom, and tendencies of epistemic freedom?

\section{Method}

\subsection{Research Design}

This is a quantitative study and follows a correlational design. As put by Weathington, Cunningham, and Pittenger (2010, p. 299), correlational research allows for the analysis of the relationships between two or more variables.

\subsection{Participants}

Convenience sampling was performed to create the sample. The sample consists of adults meeting the inclusion criterion, i.e. finished formal education. The formula " $\mathrm{N}>50+8 \mathrm{~m}$ " is used in correlational research in order to determine the sample size (Tabachnick \& Fidell, 2007). In this formula, "N" refers to the number of participants, " $\mathrm{m}$ " to the number of variables, and " 50 " to constant participants. Four variables were analyzed in the study. For the purpose of the study, the sample size was required to consist of at least 82 participants. Because 129 individuals participated in the study, the sample size was considered large and representative enough.

Presenting the demographic characteristics of the participants is necessary to appreciate and interpret from which participant profile the results have been derived. The demographic characteristics of the participants are as follows: 52 female and 77 male participants account for $40.3 \%$ and $59.7 \%$ of the sample. The ages of participants range between 22 and 67 years. The distribution is as follows: 16 participants $(12.4 \%)$ range between 22 and 29 years, 29 (22.5\%) between 30 and 39, 63 (48.8\%) between 40 and 49, 16 participants (12.4\%) between 50 and 59, and 5 (3.9\%) between 60 and over. An analysis of the marital status of the participants indicated that 113 participants (87.6\%) were married, 14 (10.9\%) were single, and 1 was divorced/widowed. 109 participants $(84.5 \%)$ and 20 participants $(15.5 \%)$ were found to have children and no children, respectively. An analysis of the participants' educational backgrounds showed that 13 participants (10.1\%) had graduated from elementary school, $6(4.7 \%)$ from middle school, $29(22.5 \%)$ from high school, while 12 (9.3\%), 64 (49.6\%), and $5(3.9 \%)$ held an associate's, bachelor's, and master's degree.

\subsection{Data Collection Tool and Data Collection}

For the purpose of the study, the data were collected with a tool developed by the researchers. The tool consists of two parts, a demographic information form and epistemic violence-freedom scale. The demographic information form offers data on the participants' gender, age, education level, marital status, parenthood. The epistemic violence-freedom scale consists of the questions "What are adults' levels of accepting education-related epistemic violence?", "To what extent do they resort to education-related epistemic violence (towards their and their relatives' children)?", "What were adults' levels of epistemic freedom in their educational background?", and "What are their tendency to education-related epistemic freedom?". The answer grids were presented in 5-point Likert scale, ranging from "totally disagree" to "totally agree". The content validity of the epistemic violence-freedom scale, consisting of 29 items, was tested by two faculty members specialized in Education Programs and Teaching. The internal consistency coefficient was taken into consideration to test the reliability. The reliability analysis for each variable showed that the scale was reliable. Descriptive data and reliability results of the tool are presented in Table 1. 
Table 1. Reliability analysis of epistemic violence-freedom scale

\begin{tabular}{lccc}
\hline Dimension & $\begin{array}{c}\text { Item } \\
\text { Number }\end{array}$ & Sample Item & $\begin{array}{c}\text { Cronbach's } \\
\text { Alpha } \\
\text { Coefficient }\end{array}$ \\
\hline $\begin{array}{c}\text { What are adults' levels of accepting } \\
\text { education-related epistemic } \\
\text { violence? }\end{array}$ & 7 & The most accurate knowledge is offered in students' textbooks. & .652 \\
$\begin{array}{c}\text { To what extent do they resort to } \\
\text { education-related epistemic } \\
\text { violence? }\end{array}$ & 5 & I impose my own views related to what is right and wrong on my & .721 \\
$\begin{array}{c}\text { What were adults' levels of } \\
\text { epistemic freedom in their } \\
\text { educational background? }\end{array}$ & 10 & $\begin{array}{c}\text { During my education, I generally used to ask, "How would you } \\
\text { know what I really want to learn"? }\end{array}$ & .794 \\
$\begin{array}{l}\text { What are their tendencies of } \\
\text { education-related epistemic } \\
\text { freedom? }\end{array}$ & 7 & $\begin{array}{c}\text { Individuals should research what kind of information/knowledge } \\
\text { they were not provided with when developing their own } \\
\text { education-related understanding/approach. }\end{array}$ & .893 \\
\hline
\end{tabular}

The data were collected by the researchers in face-to-face interviews.

\subsection{Data Analysis}

The obtained data were analyzed with SPSS 21.0 software program. Descriptive statistics (frequency, percentage, mean score, and standard deviation) were employed for descriptive analyses, while correlation analyses for correlational investigations.

\section{Results}

In this part, the results of the analyses conducted in line with the aims of the research are presented.

Table 2. Distribution of adults' levels of epistemic violence-freedom

\begin{tabular}{|c|c|c|c|c|c|c|}
\hline Dimension & & Very low & Low & Moderate & High & Very high \\
\hline \multirow{2}{*}{ What are adults' levels of accepting education-related epistemic violence? } & $\mathrm{f}$ & 0 & 13 & 62 & 52 & 2 \\
\hline & $\%$ & .0 & 10.1 & 48.1 & 40.3 & 1.6 \\
\hline \multirow{2}{*}{ To what extent do they resort to education-related epistemic violence? } & $\mathrm{f}$ & 16 & 80 & 28 & 4 & 1 \\
\hline & $\%$ & 12.4 & 62.0 & 21.7 & 3.1 & .8 \\
\hline \multirow{2}{*}{ What were adults' levels of epistemic freedom in their educational background? } & $\mathrm{f}$ & 1 & 6 & 61 & 54 & 7 \\
\hline & $\%$ & .8 & 4.7 & 47.3 & 41.9 & 5.4 \\
\hline \multirow{2}{*}{ What are their tendencies to education-related epistemic freedom? } & $\mathrm{f}$ & 0 & 2 & 19 & 77 & 31 \\
\hline & $\%$ & .0 & 1.6 & 14.7 & 59.7 & 24.0 \\
\hline
\end{tabular}

Table 2 presents adults' levels of accepting epistemic violence. The participants at a "low" level of epistemic violence acceptance account for $10.1 \%$ while there were observed no participant at a "very low" level. The results also yielded a "moderate", "high", and "very high" level of acceptance (48.1\%, 40.3\%, and 1.6\%, respectively).

The analysis of to what extent adults practice epistemic violence on others (their children or relatives) revealed that $12.4 \%$ and $62.0 \%$ practice epistemic violence at a "very low" and "low" level. In addition, it was realized that $21.7 \%, 3.1 \%, 0.8 \%$ of the participants resort to epistemic violence at a "moderate", "high", and "very high" level, respectively.

The analysis of "what were adults' levels of epistemic freedom in their educational background?" showed that $47.3 \%$ and $41.9 \%$ had a "moderate" and "high" level of epistemic freedom, respectively.

In consideration of adults' paradigm tendencies to epistemic freedom, it can be observed that the one with a "high" and "very high" level of tendency to epistemic freedom were $59.7 \%$ and $24.0 \%$, respectively.

When the aforementioned results are evaluated in terms of the groups' mean scores, adults' educational epistemologies can be more vividly accounted for. 


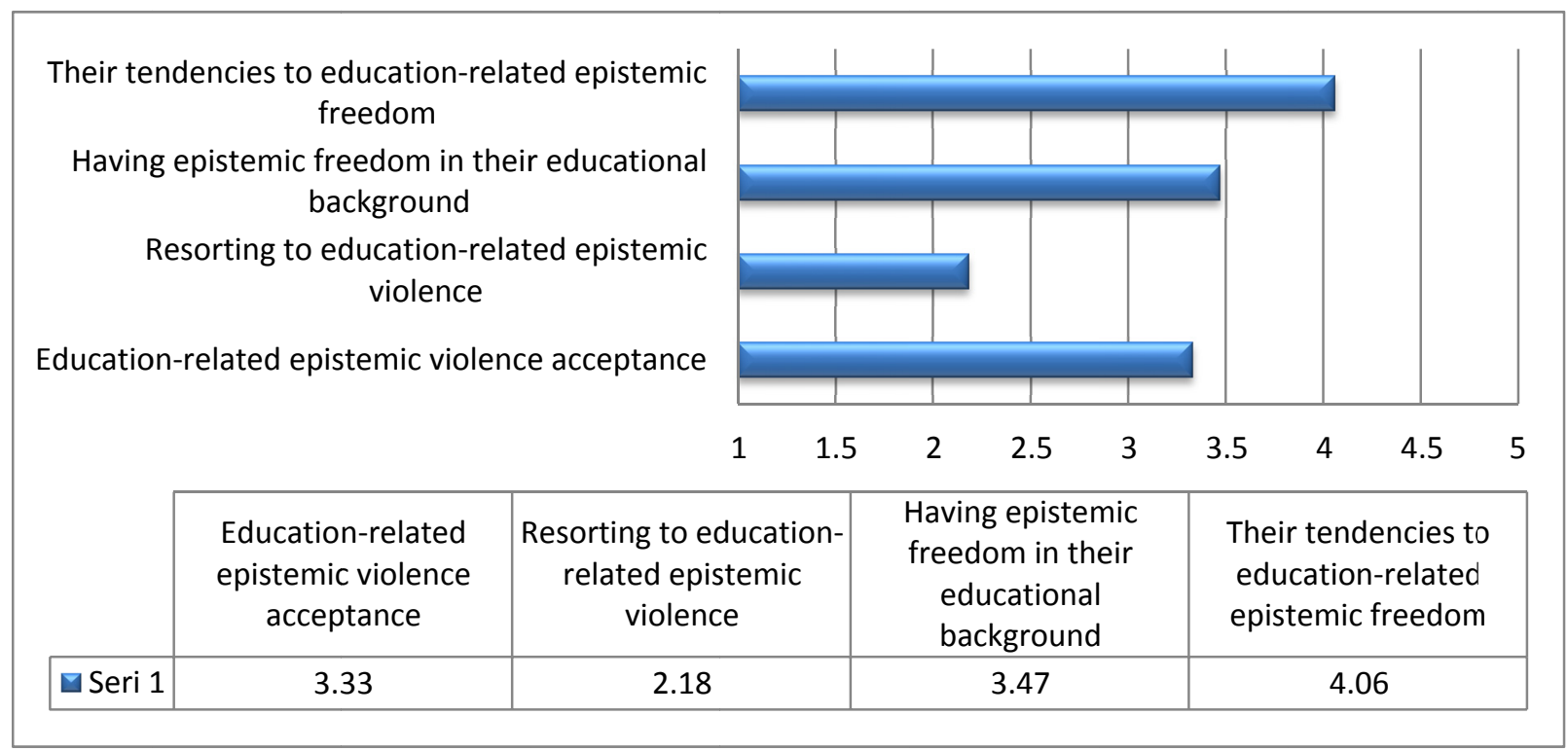

Figure 1. Adults' epistemic violence-freedom levels (mean scores: 1.00-1.49: Very low, 1.50-2.49: Low,

$$
\text { 2.50-3.49: Moderate, 3.50-4.49: High, 4.50-5.00: Very high) }
$$

Figure 1 revealed that adults' level of accepting education-related epistemic violence and resorting to education-related epistemic violence were "moderate" $(\bar{X}=3.33)$ and "low" $(\bar{X}=2.18)$, respectively, while their enjoyment of epistemic freedom in the past was between "moderate" and "high" ( $\bar{X}=3.47)$ and their tendency to education-related epistemic freedom was "high" $(\bar{X}=4.06)$.

Table 3. Analysis of the relationships between variables-Pearson's correlation analysis

\begin{tabular}{|c|c|c|c|c|}
\hline & & $\begin{array}{c}\text { Education-related epistemic } \\
\text { violence acceptance }\end{array}$ & $\begin{array}{l}\text { Resorting to education-related } \\
\text { epistemic violence }\end{array}$ & $\begin{array}{l}\text { Having epistemic freedom in } \\
\text { their educational background }\end{array}$ \\
\hline \multirow{4}{*}{$\begin{array}{c}\text { Resorting to education } \\
\text { background epistemic violence }\end{array}$} & Pearson & & & \\
\hline & Correlation & .119 & & \\
\hline & Sig. (2-tailed) & .180 & & \\
\hline & $\mathrm{N}$ & 129 & & \\
\hline \multirow{4}{*}{$\begin{array}{l}\text { Having epistemic freedom in their } \\
\text { educational background }\end{array}$} & Pearson & -065 & $-.212^{*}$ & \\
\hline & Correlation & & & \\
\hline & Sig. (2-tailed) & .463 & .016 & \\
\hline & $\mathrm{N}$ & 129 & 129 & \\
\hline \multirow{3}{*}{$\begin{array}{l}\text { Their tendencies to } \\
\text { education-related epistemic } \\
\text { freedom }\end{array}$} & $\begin{array}{l}\text { Pearson } \\
\text { Correlation }\end{array}$ & .057 & $-.334^{* *}$ & $.449^{* *}$ \\
\hline & Sig. (2-tailed) & .518 & .000 & .000 \\
\hline & $\mathrm{N}$ & 129 & 129 & 129 \\
\hline
\end{tabular}

*. Correlation is significant at the 0.05 level (2-tailed).

**. Correlation is significant at the 0.01 level (2-tailed).

The relationships between the variables are provided in Table 3. The authors found a significant, negative, and weak relationship between adults level of "resorting to epistemic violence" and the levels of "having epistemic freedom in their educational background" $(r=-.212, \mathrm{p}<.05)$ and of "their tendency to education-related epistemic freedom" ( $(\mathrm{r}=-.334, \mathrm{p}<.05)$. The authors also observed a significant, positive, and moderate relationship between adults' levels of "having epistemic freedom in their educational background" and of "their tendency to education-related epistemic freedom" $(\mathrm{r}=.449, \mathrm{p}<.05)$. No statistically significant difference was observed between the other variables. 


\section{Discussion}

The present research revealed significant results pertaining to adults' education-related epistemic freedom and epistemic violence levels.

Adults' level of accepting education-related epistemic violence was observed to be "moderate" in view of group means. However, the fact that the distributions of adults' level of accepting epistemic violence were found to be $48.1 \%$ and $40.3 \%$ at a "moderate" and "high" level, respectively, is indicative of the fact that adults had a low level of taking education-related epistemic initiative, taking epistemic risk, and exhibiting epistemic autonomy. This finding can be interpreted to conclude that adults submit to authority in terms of education and the related practices but fail to exhibit septic behaviors concerning the same aspects.

Adults' levels of practicing education-related epistemic violence on their own or relatives' children were "low". It was realized that $12.4 \%$ and $62.0 \%$ of the participants had a "very low" and "low" level, respectively. This is a concerning finding when adults' levels of accepting epistemic violence are compared. This finding can be explained as follows: It is thought that adults do not consider themselves competent or specialized/professional in education and do not practice epistemic violence. They assign the responsibility of practicing epistemic violence to authorities as experts/professionals. Another perspective is that they consider epistemic violence as a just act for the others, which may be interpreted that they are not for their own or relatives' children.

Adults' levels of having epistemic freedom in their educational background are between "moderate" and "high". The fact that $47.3 \%$ and $41.9 \%$ of the adults exhibited a "moderate" and "high" level, respectively, suggests that they have epistemic freedom. They were discovered to have held an acceptable level of epistemic freedom in their educational background and had the opportunity to take initiatives in education-related decisions and practices and to act autonomously.

Adults' tendencies to education-related epistemic freedom were found to be "high" in consideration of group mean scores. The group distribution showed that $59.7 \%$ and $24.0 \%$ of the participants had a "high" and "very high" level, respectively. They think that education-related epistemic freedom should be achieved and maintained. They advocate that no epistemic oppression and authority-based education conventions should exist, but there should be a septic perspective on education process, and individuals should be responsible for their own developments thanks to democratic education (Andrews \& Okpanachi, 2012). However, high levels of accepting epistemic violence and of tendency to epistemic freedom should be further elaborated on. This indicates a contradiction between individuals' ideals and the reality. The failure of an individual advocating epistemic freedom to practice it effectively results in the persistence of epistemic violence (Owens, 2000; Sperber et al., 2010). This should be questioned and researched.

In consideration of the abovementioned epistemic freedom and epistemic violence potentials, the present study investigated the relationships between variables to understand what the epistemic freedom opportunities are and how epistemic freedom-violence system works/operates to offer a basic perspective to further research, and to provide argumentative bases and tips for future policies. As a result of the analyses, the authors found a significant, negative, and weak relationship between adults level of "resorting to epistemic violence" and the levels of "enjoyment of education-related epistemic freedom in the past" and of "their tendency to education-related epistemic freedom". This signifies that as adults' tendency to epistemic freedom and incidences of their having epistemic freedom in their educational background increase, epistemic violence tends to subside. Therefore, the youth as future adults should be offered epistemic freedom opportunities and approaches to strengthen their tendency to epistemic freedom in their educational lives. Additionally, the authors observed a significant, positive, and moderate relationship between adults' levels of "enjoyment of education-related epistemic freedom in the past" and of "their tendency to education-related epistemic freedom". As their level of having epistemic freedom in their education increases so does their tendency to epistemic freedom (Adam, 2012; Logue, 2013; Mugny, Chatard, \& Quimzade, 2006; Mugny, Quimzade, \& Trandafir, 2006).

Education is the essential means in individuals' search for self-realization. Hence, there will be severe differences in qualifications of individuals educated in an authoritarian and liberal education setting. In this sense, the approach of each of these understanding to education is different. While learners are considered as overdependent individuals, merchandises, and capitals in the authoritarian approach, they are regarded as individuals making their own decisions and source of diversity thanks to their awareness of individual differences (Adam, 2012; Chinnery, 2013; Gelfert, 2013; Logue, 2013; Moroz, 2015; Mugny, Chatard, \& Quimzade, 2006; Mugny, Quimzade, \& Trandafir, 2006; Quiamzade, Mugny, \& Falomir-Pichastor, 2009). The determinant of these two approaches is related to at what level epistemic freedom and epistemic violence approaches are in a society and how they exist. For an open society as put by Popper (1966), epistemic violence should be stopped and epistemic freedom should 
be achieved.

\subsection{Suggestions}

In consideration of the conclusions drawn in this research study, where the existence of and the relationships between epistemic violence and epistemic freedom are investigated, the conduction of research to determine the sources of epistemic violence and epistemic freedom and resolution of existing problems are believed to prove beneficial. Additionally, down-to-ground analyses intended for actual field practices performed to prevent epistemic violence and promote epistemic freedom are needed. It is essential to develop policy-media-college-school-family-learner collaborations.

Individuals' wish to eliminate epistemic violence can be better appreciated in the cases where their tendency to epistemic freedom is high. Therefore, individuals should be rendered more competent in this matter by creating properly operating and functional micro- and macro-cultures for epistemic freedom. In this sense, the most important effort to make is the implementation of constructive approach in the framework of ontological, epistemological, and axiological assumptions.

\subsection{Limitations}

This study was conducted as a correlational research. Correlational research has some internal validity threats. So, it is suggested that conducting qualitative research such as case study can be effective for comparing results. This study is a cross-sectional research. For further research, longitudinal researches are recommended. And also, parameters that cause epistemic freedom and epistemic violence should be investigated.

\section{References}

Adam, R. J. (2012). Conceptualising the epistemic dimension of academic identity in an age of neo-liberalism. Education Research and Perspectives An International Journal, 39, 70-89.

Al-Mahadin, S. (2004). Jordanian women in education: Politics, pedagogy and gender discourses. Feminist Review, 78, 22-37. https://doi.org/10.1057/palgrave.fr.9400188

Andreotti, V., Ahenakew, C., \& Cooper, G. (2011). Epistemological pluralism: Ethical and pedagogical challenges in higher education. AlterNative: An International Journal of Indigenous Peoples, 7(1), 40-50. https://doi.org/10.1177/117718011100700104

Andrews, N., \& Okpanachi, E. (2012). Trends of epistemic oppression and academic dependency in Africa's development: The need for a new intellectual path. The Journal of Pan African Studies, 5(8), 85-103.

Bastien, B. (2004). Blackfoot ways of knowing: The worldview of the Siksinaitsitapi. Calgary: University of Calgary Press.

Battiste, M. (2004). Bringing Aboriginal education into contemporary education: Narratives of cognitive imperialism reconciling with decolonization. In J. Collard, \& C. Reynolds (Eds.), Leadership, gender and culture. Male and female perspectives (pp. 142-148). Maidenhead: Open University Press.

Chinnery, A. (2013). On epistemic vulnerability and open-mindedness. In C. Mayo (Ed.), Philosophy of Education. A Publication of the Philosophy of Education Society.

Daukas, N. (2006). Epistemic Trust and Social Location. Episteme, 3(1-2), 109-124. https://doi.org/10.3366/epi.2006.3.1-2.109

Deloria, V. (1995). Red earth, white lies, Native Americans and the myth of scientific fact. New York: Scribner.

Dotson, K. (2012). A cautionary tale: On limiting epistemic oppression. Frontiers: A Journal of Women Studies, 33(1), 24-47. https://doi.org/10.5250/fronjwomestud.33.1.0024

Galván-Álvarez, E. (2010). Epistemic violence and retaliation: The issue of knowledges in "Mother India". Atlantis Journal of the Spanish Association of Anglo-American Studies, 32(2), 11-26.

Gelfert, A. (2013). Coverage-reliability, epistemic dependence, and the problem of rumor-based belief. Philosophia, 41(3), 763-786. https://doi.org/10.1007/s11406-012-9408-z

Henning, C. (2017). Theories of Culture in the Frankfurt School of Critical Theory. In M. Thompson (Ed.), The Palgrave Handbook of Critical Theory. Political Philosophy and Public Purpose. Palgrave Macmillan, New York. https://doi.org/10.1057/978-1-137-55801-5_12

Hofer, B. K., \& Pintrich, P. R. (1997). The development of epistemological theories: Beliefs about knowledge and knowing and their relation to learning. Review of Educational Research, 67(1), 88-140. https://doi.org/10.3102/00346543067001088 
Kıncal, R. Y., Kartal, O. Y., \& Yazgan, A. D. (2018). Identification of the parameters concerning young adults' taking epistemic risks in their social media posts with academic content. 14th International Conference Mobile Learning 14-16 April 2018, Lisbon, Portugal. IADIS Press.

Koenig, M. A., \& Harris, P. L. (2007). The Basis of Epistemic Trust: Reliable Testimony or Reliable Sources? Episteme, 4(3), 264-284. https://doi.org/10.3366/E1742360007000081

Logue, J. (2013). The politics of unknowing and the virtues of ignorance: Toward a pedagogy of epistemic vulnerability. In C. Mayo (Ed.), Philosophy of Education. A Publication of the Philosophy of Education Society

Marker, M. (2003). Indigenous voice, community, and epistemic violence: The ethnographer's "interests" and what "interests" the ethnographer. International Journal of Qualitative Studies in Education, 16(3), 361-375, https://doi.org/10.1080/0951839032000086736

Moroz, J. (2015). Knowledge and reality as educational tools of violence. Power \& Education, 7(1), 113-119. https://doi.org/10.1177/1757743814567391

Mugny, G., Chatard, A., \& Quiamzade, A. (2006). The social transmission of knowledge at the university: Teaching style and epistemic dependence. European Journal of Psychology of Education, 21(4), 413-427.

Mugny, G., Quiamzade, A., \& Trandafir, A. (2006). Dépendance informationnelle et styles de comportement dans l'influence sociale. Psihologie Sociala, 17, 43-56. https://doi.org/10.1007/BF03173511

Origgi, G. (2012). Epistemic injustice and epistemic trust. Social Epistemology, 26(2), 221-235. https://doi.org/10.1080/02691728.2011.652213

Owens, D. (2000). Reason without freedom: The problem of epistemic normativity. London: Routledge.

Popper, K. R. (1966). The open society and its enemies (5th ed.). Princeton University Press.

Quiamzade, A., Mugny, G., \& Falomir-Pichastor, J. M. (2009). Epistemic constraint and teaching style. European Journal of Psychology of Education, 24(2), 181-190. https://doi.org/10.1007/BF03173010

Schommer, M. (1994). An emerging conceptualization of epistemological beliefs and their role in learning. In R. Garner, \& P. A. Alexander (Eds.), Beliefs about text and instruction with text. Lawrence Erlbaum Associates Publishers.

Schommer, M. (1998). The influence of age and education on epistemological beliefs. British Journal of Educational Psychology, 68, 551-562. https://doi.org/10.1111/j.2044-8279.1998.tb01311.x

Schommer-Aikins, M., Duell, O. K., \& Barker, S. (2003). Epistemological beliefs across domains using Biglan's classification of academic disciplines. Research in Higher Education, 44(3), 347-366. https://doi.org/10.1023/A:1023081800014

Shafto, P., Eaves, B., Navarro, D. J., \& Perfors, A. (2012). Epistemic trust: Modeling children's reasoning about others' knowledge and intent. Developmental Science, 15(3), 436-447. https://doi.org/10.1111/j.1467-7687.2012.01135.x

Sperber, D., Clement, F., Heintz, C., Mascaro, O., Mercier, H., Origgi, G., \& Wilson, D. (2010). Epistemic vigilance. Mind \& Language, 25, 359-393. https://doi.org/10.1111/j.1468-0017.2010.01394.x

Tabachnick, B. G., \& Fidell, L. S. (2007). Using multivariate statistics (5th ed.). Boston: Pearson Education, Inc.

Velleman, J. D. (2000). The Possibility of practical reason. New York: Clarendon Press.

Weathington, B. L., Cunningham, C. J. L., \& Pittenger, D. J. (2010). Research methods for the behavioral and social sciences. USA: John Wiley \& Sons, Inc.

Zagzebski, L. T. (2012). Epistemic authority: A theory of trust, authority, and autonomy in belief. Oxford University Press. https://doi.org/10.1093/acprof:oso/9780199936472.001.0001

\section{Copyrights}

Copyright for this article is retained by the author(s), with first publication rights granted to the journal.

This is an open-access article distributed under the terms and conditions of the Creative Commons Attribution license (http://creativecommons.org/licenses/by/4.0/). 